\title{
Long-term outcomes of surgery for chronic thromboembolic pulmonary hypertension compared with medical therapy at a single Korean center
}

\author{
Soo Han Kim ${ }^{1}$, Jae Won Lee ${ }^{2}$, Jung-Min Ahn³, Dae-Hee Kim³ ${ }^{3}$ Jong-Min Song 3 , Sang-Do Lee ${ }^{4}$, and \\ Jae Seung Lee ${ }^{4}$
}

\begin{abstract}
Departments of ${ }^{1}$ Internal Medicine, ${ }^{2}$ Thoracic and Cardiovascular Surgery, ${ }^{3}$ Cardiology, ${ }^{4}$ Pulmonary and Critical Care Medicine, Center for Pulmonary Hypertension and Venous Thrombosis, Asan Medical Center, University of Ulsan College of Medicine, Seoul, Korea
\end{abstract}

\author{
Received: February 22, 2016 \\ Revised : May 12, 2016 \\ Accepted: June 29, 2016

\section{Correspondence to} \\ Jae Seung Lee, M.D. \\ Department of Pulmonary and \\ Critical Care Medicine, Center \\ for Pulmonary Hypertension and \\ Venous Thrombosis, Asan \\ Medical Center, University of \\ Ulsan College of Medicine, 88 \\ Olympic-ro 43-gil, Songpa-gu, \\ Seoul 05505 , Korea \\ Tel: $+82-2-3010-3994$ \\ Fax: $+82-2-3010-6968$ \\ E-mail:jsdoc1186@daum.net
}

Background/Aims: Pulmonary endarterectomy (PEA) is the gold standard for treating chronic thromboembolic pulmonary hypertension (CTEPH) in Western countries. The aim of this study was to investigate the long-term outcomes of performing PEA on CTEPH patients in comparison with medical therapy at a single Korean center.

Methods: This retrospective study included 88 CTEPH patients. These patients were classified into the PEA group $(\mathrm{n}=37$ ) or non-PEA group (i.e., medical therapy; $\mathrm{n}=51$ ). The clinical characteristics, hemodynamic data, and long-term survival rates were compared. Independent prognostic factors for CTEPH were also investigated.

Results: CTEPH was not associated with either gender, and the mean age at diagnosis was $53.3 \pm 13.7$ years. Echocardiography revealed that the mean peak velocity of the tricuspid regurgitation jet was $4.2 \pm 0.7 \mathrm{~m} / \mathrm{sec}$ and the mean pulmonary arterial pressure was $51.7 \pm 15.1 \mathrm{mmHg}$. The PEA and non-PEA groups demonstrated no significant differences, except in terms of the right ventricular end-diastolic diameter. The survival rates of the PEA group were significantly higher than the non-PEA group at $1,3,5$, and 10 years $(p=0.032)$. Multivariate analyses indicated that World Health Organization class IV and PEA were significant predictors of poorer and better outcomes, respectively.

Conclusions: PEA demonstrates more favorable effects on long-term survival than medical therapy in Korean CTEPH patients who were considered operable.

Keywords: Korea; Pulmonary embolism; Hypertension, pulmonary; Surgery; Survival

\section{INTRODUCTION}

Chronic thromboembolic pulmonary hypertension (CTEPH) is a form of pulmonary hypertension $(\mathrm{PH})$ that is characterized by the mechanical obstruction of the pulmonary arteries with thromboembolic materials. The consequences of CTEPH—such as an increase in pulmonary vascular resistance (PVR), progressive $\mathrm{PH}$, and eventually right heart failure-are devastating [1].

Pulmonary endarterectomy (PEA) is the treatment of choice for relieving pulmonary artery (PA) obstruction in patients with CTEPH [2]. This treatment is well established by studies performed at experienced surgical centers in Western countries, in particular the University 
of California, San Diego (UCSD) [3]. However, there are only a few studies on PEA in Asian countries due to the small number of PEA cases $[4,5]$. Recent studies in Western countries also reported a decrease in the mortality rates associated with PEA as a consequence of improved surgical skills; thereby, emphasizing the effects of surgical experience on clinical outcomes $[3,6]$. This suggests that the survival rates of PEA in Asian countries might be lower than in Western countries due to limited experience.

Fortunately, new pulmonary arterial hypertension (PAH) drugs have been reportedly used on inoperable CTEPH patients. One of these novel target therapiessildenafil-reportedly improves exercise capacity and PVR. Furthermore, positive effects on survival rates have been suggested in certain types of CTEPH patients $[7,8]$.

Although a few studies from Korea on CTEPH were recently published, these studies were retrospective and limited to small populations [9-11]. The aims of our present study were to investigate the baseline characteristics of CTEPH patients and the survival rates of PEA in comparison with medical treatment at a single Korean center.

\section{METHODS}

\section{Study patients}

We performed a retrospective review of patients diagnosed with CTEPH who were referred to Asan Medical Center in Korea between January 1994 and February 2015. A diagnosis of CTEPH was defined as follows: (1) mean pulmonary artery pressure (PAP) $>25 \mathrm{mmHg}$; (2) pulmonary capillary wedge pressure $(\mathrm{PCWP})<15 \mathrm{mmHg}$ on right heart catheterization (RHC) or peak velocity of the tricuspid regurgitation (TR) jet $\geq 2.8 \mathrm{~m} / \mathrm{sec}$ with normal left ventricular function on transthoracic echocardiography (TTE); (3) $\geq 3$ months of anticoagulation; and (4) $\geq 1$ mismatched segmental perfusion defect on lung ventilation and perfusion (V/Q) scanning, chest computed tomography (CT), or pulmonary angiography $[12,13]$. In patients without RHC, laboratory tests, pulmonary function tests (PFTs), chest X-rays, V/Q scans, CT, and TTE were used to diagnose CTEPH (PH group IV, as designated by the World Health Organization [WHO] classification) and rule out $\mathrm{PH}$ groups II, III, and V.
Entry was defined as the date of the first diagnosis of CTEPH on RHC or TTE.

Surgical indications for CTEPH included PVR $>300$ dyne $\times \mathrm{sec} / \mathrm{cm}^{5}$, mean PAP $>30 \mathrm{mmHg}$, WHO functional class greater than II, surgically accessible proximal lesions in the main lobar or segmental PA, and the absence of significant comorbidities. In addition, an operability assessment was performed by a multidisciplinary board that consisted of chest surgeons, pulmonologists, cardiologists, and radiologists. After PEA, all survivors received permanent anticoagulation therapy. In the nonPEA group, warfarin was administered to all patients. Oral PAH target therapies were also administered based on the clinical data and availability of medications.

This study was approved by the Institutional Review Board (IRB) of Asan Medical Center (IRB no. 2015-0516) which waived the requirement for informed consent due to the retrospective nature of the analysis.

\section{Data collection}

Baseline data were collected from the medical charts included with the electronic medical records (EMRs) and the Asan Biomedical Research Environment. Data included gender, age at diagnosis, body mass index, duration of symptoms until diagnosis, dyspnea severity based on WHO functional class, baseline laboratory data, results of PFTs, 6-minute walking distance (6MWD), Charlson comorbidity index, and sildenafil use.

Echocardiographic studies were performed using a Philips echocardiography system (Konninklijke Philips N.V., Eindhoven, the Netherlands). Echocardiographic measurements included the ejection fraction, the diameter of both ventricles during end diastole, and the peak velocity of the TR jet. Systolic PAP was estimated using the transtricuspid gradient, as measured using the Doppler method, on multiple projections plus right atrial pressure (RAP), and the transtricuspid gradient was calculated using the modified Bernoulli equation (RAP was empirically estimated as $10 \mathrm{mmHg}$ ) [14]. Mean PAP was calculated using the following equation: mean PAP = $0.61 \times$ systolic PAP $+2[15]$.

Chest CT images were reviewed using PetaVision software (Asan Medical Center). The diameters of the main PA and aorta (A) at the level of the bifurcation of the left and right main pulmonary arteries were measured in order to calculate the PA:A ratio. 
RHC was performed at the medical intensive care unit. A 7.5-Fr Swan-Ganz catheter (Edwards Lifesciences, Irvine, CA, USA) was placed in the PA through the right internal jugular vein or subclavian vein. Baseline hemodynamic values, such as systolic PAP, diastolic PAP, mean PAP, PCWP, and mixed venous oxygen saturation, were measured. Cardiac output (CO) was measured using the thermodilution technique and a Vigilance Monitor (Edwards Lifesciences). PVR was calculated as follows: (mean PAP - mean PCWP) / CO. The cardiac index was calculated as $\mathrm{CO} /$ body surface area [14].

\section{Outcome measures}

The efficacy of PEA was evaluated by comparing patient survival status and the survival periods between the PEA and non-PEA groups. Survival status was determined using the EMRs from Asan Medical Center and the expiration date of the Korean National Health Insurance Service for each patient. The survival period was defined as the time from diagnosis to either death or the last day of hospital follow-up. The survival rates for the whole cohort and both groups were evaluated at 1, 3, 5, and 10 years after the first diagnosis. Operative mortality was defined as in-hospital mortality or death that occurred within 30 days after PEA. Late mortality was defined as mortality that occurred more than 30 days after PEA. The causes of operative and late mortality included all-cause mortality, which were also reviewed using the EMRs from Asan Medical Center.

\section{Statistical analysis}

All values are expressed as the mean \pm standard deviation or median (interquartile range) for continuous variables, or as the number or percentage for categorical variables. Baseline clinical characteristics, hemodynamic data, and RHC findings were compared using the independent $t$ test or Mann-Whitney $U$ test for continuous variables. For categorical variables, the chi-square test or linear-by-linear association test was used. Survival curves were derived using the Kaplan-Meier method and log-rank test. In this study, $p<0.05$ was considered statistically significant. Backward stepwise univariate and multivariate Cox proportional hazard models were used to examine prognostic factors and the independent effect on survival. The results are presented as hazard ratios (HR) with corresponding 95\% confidence interval
(CI). The analyses were performed using PASW statistics version 20 (IBM Co., Armonk, NY, USA).

\section{RESULTS}

\section{Baseline patient characteristics}

A total of 94 patients with CTEPH were reviewed, and 88 patients were enrolled in this study. Six patients who underwent PEA were excluded because their TR velocity was $<2.8 \mathrm{~m} / \mathrm{sec}$ (Fig. 1). As a whole, CTEPH was not found to be specifically associated with either gender, and the mean age at diagnosis was $53.3 \pm 13.7$ years. The mean peak velocity of the TR jet was $4.2 \pm 0.7 \mathrm{~m} / \mathrm{sec}$, and the mean PAP was $51.7 \pm 15.1 \mathrm{mmHg}$ on TTE. RHC indicated that the mean PAP was $46.1 \pm 12.0 \mathrm{mmHg}$, and the mean PVR was $827.4 \pm 560.3$ dyne $\times \mathrm{sec} / \mathrm{cm}^{5}$.

Table 1 presents the baseline characteristics and hemodynamic data of the CTEPH study patients based on RHC status. The RHC group consisted of 30 patients, while the non-RHC group consisted of 58 patients. There were no significant differences between the two groups, except in terms of WHO functional class (class II, III, IV: $56.7 \%, 43.3 \%$, o\% vs. $39.7 \%, 48.3 \%, 12.1 \%$, respectively; $p=0.040$ ), sildenafil use (70\% vs. $19 \%, p<0.001)$, and PA diameter $(30.4 \pm 4.6 \mathrm{~mm}$ vs. $33.0 \pm 5.1 \mathrm{~mm}, p=0.036)$.

The baseline characteristics of the CTEPH patients based on PEA status are summarized in Table 2. The

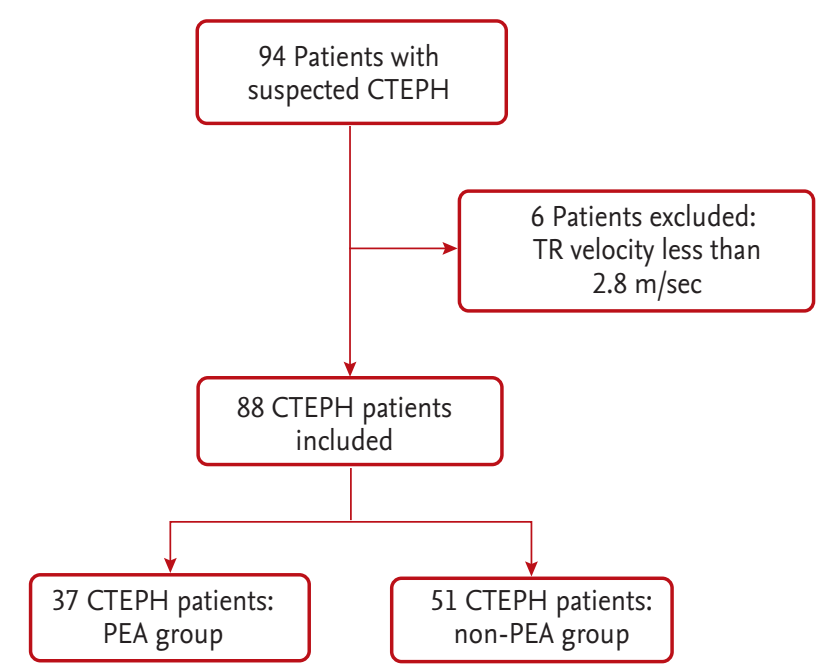

Figure 1. Flow diagram of patient selection. CTEPH, chronic thromboembolic pulmonary hypertension; TR, tricuspid regurgitation; PEA, pulmonary endarterectomy. 
Table 1. Comparison of the baseline characteristics between the RHC and non-RHC groups

\begin{tabular}{|c|c|c|c|c|}
\hline Characteristic & All patients $(\mathrm{n}=88)$ & RHC group $(\mathrm{n}=30)$ & $\begin{array}{l}\text { Non-RHC group } \\
\qquad\left(\mathrm{n}=5^{8}\right)\end{array}$ & $p$ value \\
\hline Female sex ${ }^{\mathrm{a}}$ & $40(45 \cdot 5)$ & $15(50.0)$ & $25(43.1)$ & 0.538 \\
\hline Age at diagnosis, $\mathrm{yr}^{\mathrm{b}}$ & $53.3 \pm 13.7$ & $50.9 \pm 15 \cdot 3$ & $54.6 \pm 12.8$ & 0.237 \\
\hline Body mass index, $\mathrm{kg} / \mathrm{m}^{2 \mathrm{~b}}$ & $23.9 \pm 3.2$ & $23.8 \pm 3.7$ & $23.9 \pm 2.9$ & 0.837 \\
\hline $\begin{array}{l}\text { Time to diagnosis from the } \\
\text { onset of symptoms, mon }{ }^{c}\end{array}$ & $24.0(12.0-60.0)$ & $24.0(13.5-72.0)$ & $21.0(10.0-60.0)$ & 0.919 \\
\hline WHO functional class ${ }^{\mathrm{d}}$ & & & & 0.040 \\
\hline Class I & 0 & o & o & \\
\hline Class II & $40(45 \cdot 5)$ & $17(56.7)$ & $23(39 \cdot 7)$ & \\
\hline Class III & $41(46.6)$ & $13(43 \cdot 3)$ & $28(48.3)$ & \\
\hline Class IV & $7(8.0)$ & o & $7(12.1)$ & \\
\hline \multicolumn{5}{|l|}{ PFT, \% pred ${ }^{b}$} \\
\hline FEV1 & $81.0 \pm 17.5(\mathrm{n}=75)$ & $81.2 \pm 19.3(n=28)$ & $81.0 \pm 16.6(n=47)$ & 0.957 \\
\hline FVC & $86.2 \pm 17.0(\mathrm{n}=75)$ & $87.2 \pm 17.0(n=28)$ & $85.6 \pm 17.1(n=47)$ & 0.696 \\
\hline $\mathrm{DL}_{\mathrm{CO}}$ & $74.9 \pm 21.8(\mathrm{n}=55)$ & $73.8 \pm 22.1(n=21)$ & $75.5 \pm 22.0(n=34)$ & 0.774 \\
\hline 6MWD, m & $389.0 \pm 132.5(n=43)$ & $403.2 \pm 111.6(n=21)$ & $375.4 \pm 151.1(n=22)$ & 0.497 \\
\hline Charlson comorbidity index ${ }^{c}$ & $2.0(1.0-3.0)$ & $2.0(1.0-3.0)$ & $2.0(1.0-3.0)$ & 0.604 \\
\hline Sildenafil use ${ }^{a}$ & $32(36.4)$ & $21(70.0)$ & $11(19.0)$ & $<0.001$ \\
\hline \multicolumn{5}{|l|}{ TTE findings } \\
\hline $\mathrm{EF}, \%^{\mathrm{c}}$ & $64.5(59.0-69.0)(n=88)$ & $63.0(60.8-69.0)(n=30)$ & $65.0(57.0-69 \cdot 3)(\mathrm{n}=58)$ & 0.558 \\
\hline LVEDD, $\mathrm{mm}^{\mathrm{c}}$ & $43.0(39.0-47.0)(n=87)$ & $43.0(40.5-47.0)(n=30)$ & $42.0(38.0-46.5)(n=57)$ & 0.540 \\
\hline RVEDD, $\mathrm{mm}^{\mathrm{c}}$ & $36.0(32.0-41.0)(n=55)$ & $36.5(31.8-40.5)(n=20)$ & $34.0(32.0-42.0)(n=35)$ & 0.793 \\
\hline TR velocity, m/sec ${ }^{\mathrm{b}}$ & $4.1 \pm 0.8(n=88)$ & $4.3 \pm 0.7(n=30)$ & $4.1 \pm 0.7(n=58)$ & 0.261 \\
\hline Systolic PAP, $\mathrm{mmHg}^{\mathrm{c}}$ & $78.9(62.6-94.6)(n=88)$ & $80.6(67.8-99 \cdot 3)(n=30)$ & $74.0(58.3-94.6)(n=58)$ & 0.250 \\
\hline Mean PAP, $\mathrm{mmHg}^{\mathrm{c}}$ & $50.1(40.2-59.7)(\mathrm{n}=88)$ & $51.1(43.3-62.6)(n=30)$ & $47.1(37.6-59.7)(\mathrm{n}=58)$ & 0.250 \\
\hline \multicolumn{5}{|l|}{ Vessel diameter on chest CT } \\
\hline PA diameter, $\mathrm{mm}^{\mathrm{b}}$ & $32.3 \pm 5.4(\mathrm{n}=75)$ & $30.4 \pm 4.6(n=27)$ & $33.0 \pm 5.1(n=48)$ & 0.036 \\
\hline Aorta diameter, $\mathrm{mm}^{\mathrm{c}}$ & $36.0(29.0-35.0)(n=75)$ & $35.0(33.0-39.0)(n=27)$ & $37.0(33 \cdot 3-41.0)(n=48)$ & 0.367 \\
\hline PA:A ratio ${ }^{c}$ & $1.1(1.0-1.4)(\mathrm{n}=75)$ & $1.1(1.1-1.5)(\mathrm{n}=27)$ & $1.1(1.0-1.3)(n=48)$ & 0.106 \\
\hline
\end{tabular}

Values are presented as number (\%), mean $\pm \mathrm{SD}$, or median $(25 \%-75 \%$ interquartile range).

RHC, right heart catheterization; WHO, World Health Organization; PFT, pulmonary function test; pred, predicted; FEV1, forced expiratory volume in 1 second; FVC, forced vital capacity; $\mathrm{DL}_{\mathrm{CO}}$, diffusing capacity; 6MWD, 6-minute walking distance; TTE, transthoracic echocardiography; EF, ejection fraction; LVEDD, left ventricular end-diastolic diameter; RVEDD, right ventricular end-diastolic diameter; TR, tricuspid regurgitation; PAP, pulmonary artery pressure; PA, pulmonary artery; A, aorta.

${ }^{a}$ Pearson chi-square test. ${ }^{b}$ The independent $t$ test. ${ }^{c}$ Mann-Whitney test. ${ }^{d}$ Linear-by-linear association.

PEA group consisted of 37 patients, while the non-PEA group consisted of 51 patients. There were no significant differences in the baseline characteristics between the PEA group and the non-PEA group. Table 3 presents the hemodynamic findings of the CTEPH patients based on PEA status. No significant differences were seen between the two groups, with the exception of the mean right ventricular end-diastolic diameter which was higher in the PEA group (38.0 $\mathrm{mm}$ [interquartile range, 34.0 to 42.8 ] vs. $34.0 \mathrm{~mm}$ [interquartile range, 28.0 to 41.0 ], $p=0.046$ ).

The RHC findings of the CTEPH patients based on PEA status are listed in Table 4. Of the 30 patients who 
Table 2. Comparison of the baseline characteristics between the PEA and non-PEA groups

\begin{tabular}{|c|c|c|c|c|}
\hline Characteristic & All patients $(\mathrm{n}=88)$ & PEA group $(n=37)$ & Non-PEA group $(n=51)$ & $p$ value \\
\hline Female sex ${ }^{a}$ & $40(45.5)$ & $14(37.8)$ & $26(51.0)$ & 0.222 \\
\hline Age at diagnosis, $\mathrm{yr}^{\mathrm{b}}$ & $53.3 \pm 13.7$ & $52.6 \pm 12.6$ & $53.8 \pm 14.6$ & 0.676 \\
\hline Body mass index, $\mathrm{kg} / \mathrm{m}^{2 \mathrm{c}}$ & $23.6(21.7-25.4)$ & $23.9(22.4-25.5)$ & $23.1(21.3-25.2)$ & 0.205 \\
\hline $\begin{array}{l}\text { Time to diagnosis from the } \\
\text { onset of symptoms }\end{array}$ & $24.0(12.0-60.0)$ & $24.0(9.0-60.0)$ & $24.0(12.0-60.0)$ & 0.976 \\
\hline WHO functional class ${ }^{\mathrm{d}}$ & & & & 0.765 \\
\hline Class I & o & o & o & \\
\hline Class II & $40(45.5)$ & $14(37.8)$ & $26(51.0)$ & \\
\hline Class III & $41(46.6)$ & $22(59.5)$ & $19(37.3)$ & \\
\hline Class IV & $7(8.0)$ & $1(2.7)$ & $6(11.8)$ & \\
\hline \multicolumn{5}{|l|}{ PFT, \% pred ${ }^{\mathrm{b}}$} \\
\hline FEV1 & $81.0 \pm 17.5(n=75)$ & $81.8 \pm 14.2(n=30)$ & $80.5 \pm 19.6(n=45)$ & 0.734 \\
\hline FVC & $86.2 \pm 17.0(\mathrm{n}=75)$ & $86.7 \pm 15.3(n=30)$ & $85.8 \pm 18.2(\mathrm{n}=45)$ & 0.818 \\
\hline $\mathrm{DL}_{\mathrm{CO}}$ & $74.9 \pm 21.8(\mathrm{n}=55)$ & $73.1 \pm 20.7(n=21)$ & $76.0 \pm 22.8(n=34)$ & 0.634 \\
\hline $6 \mathrm{MWD}, \mathrm{m}^{\mathrm{c}}$ & $\begin{array}{c}389.0(336.0-490.0) \\
(n=43)\end{array}$ & $\begin{array}{c}380.0(300.0-491.0) \\
(\mathrm{n}=17)\end{array}$ & $\begin{array}{c}417.5(350.3-494.8) \\
(n=26)\end{array}$ & 0.427 \\
\hline Charlson comorbidity index ${ }^{c}$ & $2.2(1.0-3.0)$ & $2.0(1.0-3.0)$ & $2.0(1.0-4.0)$ & 0.384 \\
\hline Sildenafil use $^{\mathrm{a}}$ & $32(36.4)$ & $13(35.1)$ & $19(37.3)$ & 0.838 \\
\hline
\end{tabular}

Values are presented as number (\%), mean $\pm \mathrm{SD}$, or median (25\%-75\% interquartile range).

PEA, pulmonary endarterectomy; WHO, World Health Organization; PFT, pulmonary function test; pred, predicted; FEV1, forced expiratory volume in 1 second; $\mathrm{FVC}$, forced vital capacity; $\mathrm{DL}_{\mathrm{CO}}$, diffusing capacity; $6 \mathrm{MWD}$, 6-minute walking distance. ${ }^{\mathrm{a}}$ Pearson chi-square test. ${ }^{\mathrm{b}}$ The independent $t$ test, ${ }^{\mathrm{c}}$ Mann-Whitney test. ${ }^{\mathrm{d}}$ Linear-by-linear association.

Table 3. Comparison of the hemodynamic findings between the PEA and non-PEA groups

\begin{tabular}{|c|c|c|c|c|}
\hline Hemodynamic finding & All patients $(\mathrm{n}=88)$ & PEA group $(n=37)$ & Non-PEA group $(n=51)$ & $p$ value \\
\hline \multicolumn{5}{|l|}{ TTE findings } \\
\hline $\mathrm{EF}, \%^{\mathrm{a}}$ & $64.5(59.0-69.0)(n=88)$ & $65.0(59.5-69.0)(\mathrm{n}=37)$ & $63.0(59.0-68.0)(n=51)$ & 0.552 \\
\hline LVEDD, $\mathrm{mm}^{\mathrm{a}}$ & $43.0(39.0-47.0)(n=87)$ & $42.0(39.0-46.0)(n=37)$ & $43.0(38.0-47.3)(n=50)$ & 0.697 \\
\hline $\mathrm{RVEDD}, \mathrm{mm}^{\mathrm{a}}$ & $36.0(32.0-41.0)(n=55)$ & $38.0(34.0-42.8)(n=24)$ & $34.0(28.0-41.0)(n=31)$ & 0.046 \\
\hline TR velocity, $\mathrm{m} / \mathrm{sec}^{\mathrm{b}}$ & $4.2 \pm 0.7(n=88)$ & $4.3 \pm 0.7(\mathrm{n}=37)$ & $4.1 \pm 0.7(n=51)$ & 0.173 \\
\hline Systolic PAP, $\mathrm{mmHg}^{\mathrm{b}}$ & $81.5 \pm 24.8(n=88)$ & $85.7 \pm 25.9(\mathrm{n}=37)$ & $78.4 \pm 23.7(n=51)$ & 0.177 \\
\hline Mean PAP, $\mathrm{mmHg}^{\mathrm{b}}$ & $51.7 \pm 15.1(n=88)$ & $54.3 \pm 15.8(\mathrm{n}=37)$ & $49.8 \pm 14.5(n=51)$ & 0.177 \\
\hline \multicolumn{5}{|c|}{ Vessel diameter on chest CT } \\
\hline $\begin{array}{l}\text { Pulmonary artery } \\
\text { diameter, } \mathrm{mm}^{\mathrm{b}}\end{array}$ & $32.1 \pm 5.1(n=75)$ & $32.5 \pm 5.4(n=35)$ & $31.7 \pm 4.8(n=40)$ & 0.477 \\
\hline Aorta diameter, $\mathrm{mm}^{\mathrm{a}}$ & $36.0(33.0-40.0)(n=75)$ & $36.0(34.0-41.0)(n=35)$ & $36.5(33.0-39.0)(n=40)$ & 0.947 \\
\hline PA:A ratio ${ }^{\mathrm{a}}$ & $1.1(1.0-1.4)(n=75)$ & $1.1(1.0-1.5)(\mathrm{n}=35)$ & $1.1(1.0-1.3)(n=40)$ & 0.596 \\
\hline
\end{tabular}

Values are presented as median (25\%-75\% interquartile range) or mean \pm SD.

PEA, pulmonary endarterectomy; TTE, transthoracic echocardiography; EF, ejection fraction; LVEDD, left ventricular end-diastolic diameter; RVEDD, right ventricular end-diastolic diameter; TR, tricuspid regurgitation; PAP; pulmonary artery pressure; CT, computed tomography; PA, pulmonary artery; A, aorta.

${ }^{\mathrm{a}}$ Mann-Whitney test. ${ }^{\mathrm{b}}$ The independent $t$ test. 
Table 4. Comparison of the RHC findings between the PEA and non-PEA groups

\begin{tabular}{lcccc}
\hline RHC findings & All patients $(\mathrm{n}=30)$ & PEA group $(\mathrm{n}=10)$ & Non-PEA group $(\mathrm{n}=20)$ & $p$ value \\
\hline Systolic PAP, $\mathrm{mmHg}^{\mathrm{a}}$ & $78.3 \pm 21.3$ & $75.6 \pm 15.4$ & $79.7 \pm 24.0$ & 0.632 \\
Mean PAP, $\mathrm{mmHg}^{\mathrm{a}}$ & $46.1 \pm 12.0$ & $43.5 \pm 9.7$ & $47.4 \pm 13.1$ & 0.412 \\
Diastolic PAP, $\mathrm{mmHg}^{\mathrm{a}}$ & $28.3 \pm 9.8$ & $25.8 \pm 8.9$ & $29.5 \pm 10.2$ & 0.340 \\
PVR, dyne $\times \mathrm{sec} / \mathrm{cm}^{5 \mathrm{a}}$ & $827.4 \pm 560.3(\mathrm{n}=19)$ & $602.2 \pm 239.0(\mathrm{n}=9)$ & $1030.1 \pm 693.3(\mathrm{n}=10)$ & 0.093 \\
PCWP, $\mathrm{mmHg}^{\mathrm{b}}$ & $10.5(7.8-3.3)(\mathrm{n}=26)$ & $11.0(8.5-13.4)(\mathrm{n}=10)$ & $10.5(3.5-13.8)(\mathrm{n}=16)$ & 0.732 \\
CO, L/min & $4.3 \pm 1.4(\mathrm{n}=20)$ & $4.3 \pm 1.1(\mathrm{n}=9)$ & $4.3 \pm 1.7(\mathrm{n}=11)$ & 0.975 \\
CI, L/min $/ \mathrm{m}^{2 \mathrm{a}}$ & $2.6 \pm 1.0(\mathrm{n}=20)$ & $2.4 \pm 0.7(\mathrm{n}=9)$ & $2.8 \pm 1.2(\mathrm{n}=11)$ & 0.497 \\
\hline
\end{tabular}

Values are presented as mean $\pm \mathrm{SD}$ or median $(25 \%-75 \%$ interquartile range).

RHC, right heart catheterization; PEA, pulmonary endarterectomy; PAP, pulmonary artery pressure; PVR, pulmonary vascular resistance; PCWP, pulmonary capillary wedge pressure; CO, cardiac output; CI, cardiac index.

${ }^{\mathrm{a}}$ The independent $t$ test. ${ }^{\mathrm{b}}$ Mann-Whitney test.

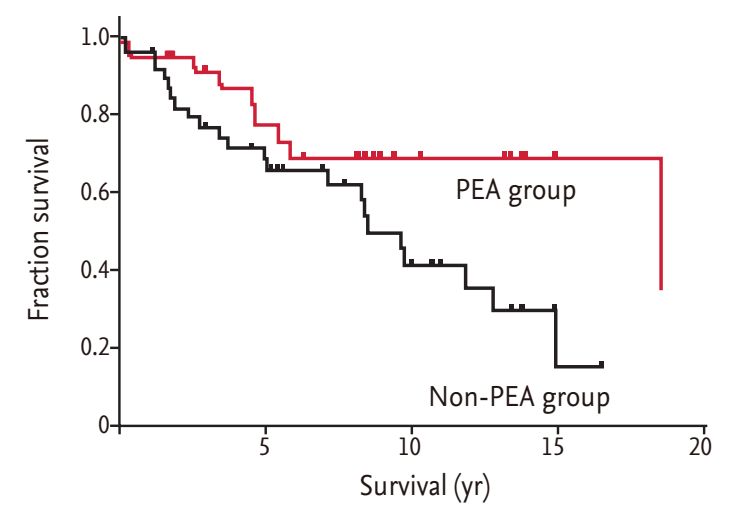

\begin{tabular}{|l|c|c|c|c|c|c|c|}
\hline No. at risk & $0 \mathrm{yr}$ & $1 \mathrm{yr}$ & $3 \mathrm{yr}$ & $5 \mathrm{yr}$ & $10 \mathrm{yr}$ & $15 \mathrm{yr}$ & No. of death \\
\hline PEA group & 37 & 30 & 21 & 17 & 8 & 2 & 9 \\
\hline Non-PEA group & 51 & 42 & 29 & 23 & 9 & 1 & 24 \\
\hline
\end{tabular}

Figure 2. Survival analysis of the chronic thromboembolic pulmonary hypertension patients based on the pulmonary endarterectomy (PEA) status $(p=0.032$, according to the Kaplan-Meier method).

underwent RHC, 10 patients were in the PEA group and 20 patients were in the non-PEA group. The mean PAP, PVR, and cardiac index values were lower in the PEA group, while the mean PCWP and CO were similar between groups. No clinically significant differences regarding RHC data were observed between groups.

\section{Survival}

The median follow-up period was 11.8 years, and 33 patients died. Nine patients died in the PEA group ( $\mathrm{n}=$ 37), while 24 patients died in the non-PEA group $(n=51)$.

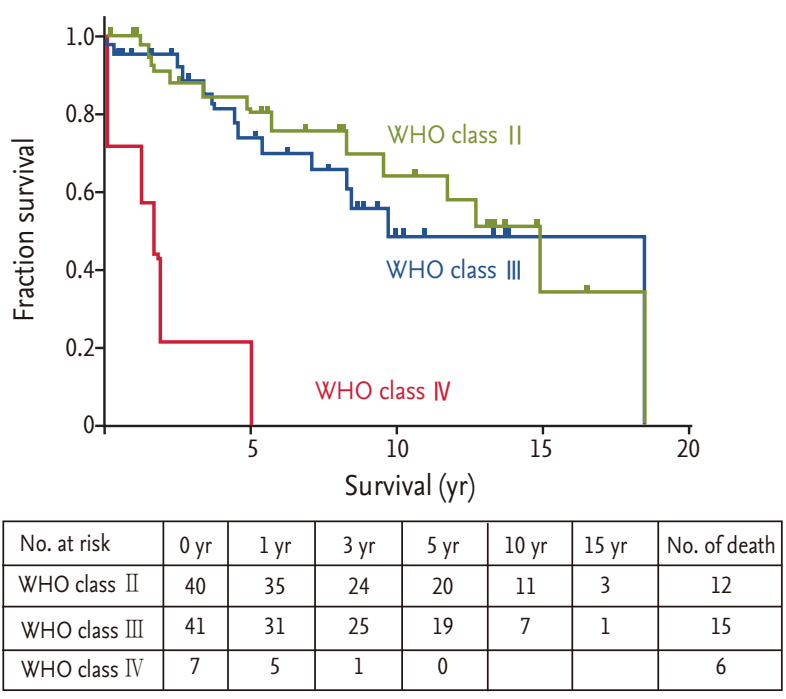

Figure 3. Survival analysis of the chronic thromboembolic pulmonary hypertension patients based on the World Health Organization (WHO) classification $(p<0.001$, according to the Kaplan-Meier method).

The survival rates of all of our CTEPH study patients at $1,3,5$, and 10 years were $94.1 \%, 81.2 \%, 69.4 \%$, and $50.7 \%$, respectively. The survival rates were $94.5 \%, 90.7 \%, 77.3 \%$, and $68.2 \%$ for the PEA group at $1,3,5$, and 10 years, and 93.9\%, 75.0\%, 64.3\%, and 40.3\% for the non-PEA group, respectively. The Kaplan-Meier method indicated that the survival rate of the PEA group was significantly better than the non-PEA group ( $p=0.032$ ) (Fig. 2). Regarding the nine deaths in the PEA group, early mortalities accounted for four deaths, and the other five deaths were associated with late mortality. The early mortalities 
Table 5. Univariate and multivariate analyses of the prognostic factors for survival in the chronic thromboembolic pulmonary hypertension patients

\begin{tabular}{|c|c|c|c|c|}
\hline \multirow{2}{*}{ Variable } & \multicolumn{2}{|c|}{ Univariate analysis } & \multicolumn{2}{|c|}{ Multivariate analysis } \\
\hline & $\mathrm{HR}(95 \% \mathrm{CI})$ & $p$ value & $\operatorname{HR}(95 \% \mathrm{CI})$ & $p$ value \\
\hline Female sex & $0.687(0.340-1.387)$ & 0.295 & & \\
\hline Age at diagnosis & $1.003(0.976-1.030)$ & 0.844 & & \\
\hline WHO class (class II standards) & & $<0.001$ & & $<0.001$ \\
\hline Class III & $10.071(3.366-30.134)$ & 0.384 & & \\
\hline Class IV & $0.957(3.706-32.393)$ & $<0.001$ & $10.071(3.366-30.134)$ & $<0.001$ \\
\hline Pulmonary endarterectomy & $0.427(0.192-0.952)$ & 0.038 & $0.413(0.177-0.963)$ & 0.041 \\
\hline Comorbidity index & $1.115(0.833-1.491)$ & 0.465 & & \\
\hline Sildenafil & $0.746(0.332-1.673)$ & 0.476 & & \\
\hline
\end{tabular}

Statistical comparisons were performed using Cox regression analysis.

HR, hazard ratio; CI, confidence interval; WHO, World Health Organization.

consisted of two patients with bleeding and two patients with right heart failure. The late mortalities consisted of two patients with $\mathrm{PH}$ aggravation and three patients with unknown causes of death.

Survival curves were also generated for WHO functional class, which is one of the main criteria for assessing operability. According to this analysis, a lower WHO functional class resulted in a better survival rate for CTEPH patients $(p<0.001)$ (Fig. 3 ).

Univariate Cox proportional hazard analysis included gender, age, WHO functional class, PEA status, Charlson comorbidity index, and sildenafil use as variables. This analysis showed that WHO functional class IV ( $p$ $<0.001)$ and PEA $(p=0.038)$ were significant predictors of survival rates. By multivariate analysis, a WHO functional class IV was negatively associated with survival (HR, 10.071; 95\% CI, 3.366 to 30.134; $p<0.001$ ), whereas a PEA was positively associated with survival (HR, o.413; $95 \%$ CI, 0.177 to $0.963 ; p=0.041$ ( (Table 5 ).

\section{DISCUSSION}

In our present study, PEA demonstrated significantly favorable outcomes in comparison with medical treatment. This is consistent with previous studies from Western countries, where the survival rates at 1 and 3 years were $88 \%$ and $76 \%$ for the surgical group and $82 \%$ and $70 \%$ for the medically treated group, respectively [16]. In addition, the survival rates of the surgical group were significantly higher than those of the medically treated group $(p=0.023)[16]$. To the best of our knowledge, our current study is the first to report the long-term survival outcomes and prove the superiority of PEA in comparison with medical treatment in Korean CTEPH patients who were appropriate for surgery.

Although the surgical outcomes of CTEPH have improved in Western countries, a grim outlook remains for Korean CTEPH patients. CTEPH is a rare disease with a worldwide incidence of approximately $4 \%$ (interquartile range, $0.4 \%$ to $9.1 \%$ ) among patients who survive an episode of acute pulmonary embolism (PE) $[1,12]$. About 60 to 100 cases of PE per 100,000 individuals occur on average in Europe and the United States [17]. Choi reported that the incidence of symptomatic CTEPH after PE in Korea was $1.9 \%$ at 6 months, $3.2 \%$ at 1 year, and $3.9 \%$ at 3 years [18]. In addition, the incidence of PE was 7.01 per 100,000 individuals according to 2008 data from the Korean Health Insurance Service [19]. Combined with the low performance of PEA in Korea, the exact diagnosis and treatment of CTEPH is often delayed due to nonspecific symptoms and a lack of PE history. This may have caused the misdiagnosis and under-recognition of CTEPH, thereby leading to poor outcomes. Assessing risk factors, increasing awareness in patients who have had a recent PE, developing guidelines for the multidisciplinary management of post-PE patients, and creating specialized referral centers are warranted in order to enhance the accurate diagnosis of CTEPH [20].

There are previously published reports on the baseline 
characteristics of CTEPH patients in Korea, but these studies used smaller cohorts than our current series [911]. The baseline characteristics of Korean CTEPH patients in our present study differ from those of Western countries in some aspects. The mean age at diagnosis for our Korean CTEPH patients was $53.3 \pm 13.7$ years, but was reported to be 63 years (interquartile range, 51 to 72 ) for Western patients. In addition, the median time from the presentation of symptoms to diagnosis in Korea is longer than in Western countries (24.0 months [interquartile range, 12.0 to 60.0 ] vs. 14.1 months [interquartile range, 7.5 to 32.8]) [21]. The differences in both age and time to diagnosis could be attributed to the increase in information about the disease, awareness among elderly patients, patient access to information, and the use of noninvasive screening tools in Western countries. Interestingly, the baseline profiles of Korean CTEPH patients are similar to Japanese CTEPH patients [22]. This could be attributed to similarities in terms of race and environment.

Before PEA was introduced, the mean survival of CTEPH patients was 6.8 years with a 3-year mortality rate of approximately $90 \%$ in patients with a mean $\mathrm{PAP}>50 \mathrm{mmHg}$ $[23,24]$. After PEA was introduced, the cumulative 5-year survival rate after PEA in Western countries was $84 \%$, which is higher than that found in our current study series (77.3\%) [25]. Furthermore, an in-hospital mortality rate of $2.2 \%$ was reported by a retrospective study of the 500 most recent cases at UCSD in comparison with $5.2 \%$ for the preceding 1,000 cases [26]. This implies the importance of surgical experience on clinical outcomes after PEA.

We observed an early mortality rate of $10.8 \%$ (four deaths) in our PEA group. This is higher than the early mortality rates previously reported by Japanese centers $(7.4 \%$ in 2009$)$ and European centers $(4.7 \%$ in 2007 to 2009), where 40 and $>50$ instances of PEA were performed per year, respectively $[4,6]$. This difference may be attributed to the low performance of RHC at our center, which limits the evaluation of perioperative risk. Imaging techniques such as pulmonary angiography, RHC, and a multidisciplinary team approach are needed to accurately assess operability [26]. Although we have performed 37 PEA procedures since 1994, UCSD has performed more than 3,000 such operations since 1970 [26]. Nevertheless, we have an optimistic view of administering PEA in Korea, as our current analysis revealed better survival outcomes for PEA than medical treatment in a center where fewer than 10 cases are performed every year. We hope that more Korean tertiary hospitals will soon achieve the surgical outcomes of Western countries in this respect [4]. To achieve this, CTEPH should be monitored at a specialized institution using a multidisciplinary approach. Such institutions should be equipped with RHC, CT, and angiography so that the selection of PEA based on systemic preoperative workup can be performed. Furthermore, the availability of bronchial artery embolization in cases of postoperative bleeding may also contribute to better survival outcomes.

As expected, WHO functional class IV and PEA were shown to be independent risk factors for CTEPH patients in both univariate and multivariate Cox regression analyses $[26,27]$. Thus, in cases of appropriate operability, PEA should be strongly considered for patients with WHO functional class IV in order to improve long-term outcomes. However, our current analysis did not identify sildenafil as an independent variable by univariate analysis. Sildenafil is a selective inhibitor of cyclic guanosine monophosphate-specific phosphodiesterase- 5 and has shown efficacy in treating idiopathic pulmonary arterial hypertension (IPAH) by enhancing nitric oxide-mediated vasodilatation [28]. Based on the similarities of CTEPH with IPAH in terms of clinical symptoms, hemodynamics, and histopathological findings, sildenafil has been used off-label to treat CTEPH [8]. This drug has been shown to enhance WHO functional class and PVR, but not 6MWD, in CTEPH patients [7]. Theoretically, preoperative medical treatment may be considered for distal forms with severe hemodynamics in order to reverse microvascular disease. However, the benefits of preoperative medical treatments are not proven, and further studies are warranted regarding this issue. The results of our current study could be attributed to the small number of sildenafil users included in our cohorts.

Recently, riociguat-a soluble guanylate cyclase stimulator-was approved for the treatment of inoperable CTEPH [29]. Additionally, percutaneous transcatheter balloon angioplasty has been shown to significantly enhance clinical outcomes, including hemodynamics, in certain groups of inoperable CTEPH patients [30]. If these treatments are introduced in Korea, an improvement in the survival rate among inoperable Korean 


\section{CTEPH patients might be expected.}

Our study had several limitations of note. First, our patients were all recruited from a single tertiary center, and our analysis was retrospective in nature. Therefore, we cannot exclude the possibility of selection bias. We also could not locate follow-up RHC and 6MWD data following PEA in some of our patients, thereby making it difficult to assess quality of life after surgery. Furthermore, we could not check the operability of every single patient. Second, the number of target patients was small and larger sample sizes will be needed to make a definitive conclusion regarding PEA. Third, most of our data were evaluated using TTE rather than RHC which may have concealed distal arteriopathy on preoperative evaluations, thereby resulting in poor surgical outcomes.

\section{KEY MESSAGE}

1. Pulmonary endarterectomy demonstrates more favorable effects on long-term survival than medical treatment in Korean chronic thromboembolic pulmonary hypertension (CTEPH) patients who were considered operable.

2. A specialized CTEPH referral center (where more precise patient evaluations, selection, and surgical protocols can be used) is warranted to achieve more accurate diagnoses and better survival outcomes in Korean CTEPH patients.

\section{Conflict of interest}

No potential conflict of interest relevant to this article was reported.

\section{REFERENCES}

1. Lang I. Chronic thromboembolic pulmonary hypertension: a distinct disease entity. Eur Respir Rev 2015;24:246252.

2. Kim NH, Delcroix M, Jenkins DP, et al. Chronic thromboembolic pulmonary hypertension. J Am Coll Cardiol 2013;62(25 Suppl):D92-D99.

3. Madani MM, Auger WR, Pretorius V, et al. Pulmonary endarterectomy: recent changes in a single institution's experience of more than 2,700 patients. Ann Thorac Surg
2012;94:97-103

4. Ogino $\mathrm{H}$. Recent advances of pulmonary endarterectomy for chronic thromboembolic pulmonary hypertension including Japanese experiences. Gen Thorac Cardiovasc Surg 2014;62:9-18.

5. Li YD, Zhai ZG, Wu YF, et al. Improvement of right ventricular dysfunction after pulmonary endarterectomy in patients with chronic thromboembolic pulmonary hypertension: utility of echocardiography to demonstrate restoration of the right ventricle during 2-year follow-up. Thromb Res 2013;131:e196-e201.

6. Mayer E, Jenkins D, Lindner J, et al. Surgical management and outcome of patients with chronic thromboembolic pulmonary hypertension: results from an international prospective registry. J Thorac Cardiovasc Surg 2011;141:702-710.

7. Suntharalingam J, Treacy CM, Doughty NJ, et al. Longterm use of sildenafil in inoperable chronic thromboembolic pulmonary hypertension. Chest 2008;134:229-236.

8. Hoeper MM. Pharmacological therapy for patients with chronic thromboembolic pulmonary hypertension. Eur Respir Rev 2015;24:272-282.

9. Oh SJ, Bok JS, Hwang HY, Kim KH, Kim KB, Ahn H. Clinical outcomes of thromboendarterectomy for chronic thromboembolic pulmonary hypertension: 12-year experience. Korean J Thorac Cardiovasc Surg 2013;46:41-48.

10. Kim HK, Hong SC, Lee JW, et al. Effects of pulmonary thromboendarterectomy in patients with chronic thromboembolic pulmonary hypertension. Tuberc Respir Dis 2005;59:644-650.

11. Lim JY, Lee JW, Kim JW, et al. Clinical results after pulmonary endarterectomy as a curative surgical method in chronic thromboembolic pulmonary hypertension: an approach to operative classification of thromboembolic disease. Korean J Thorac Cardiovasc Surg 2008;41:591-597.

12. Guerin L, Couturaud F, Parent F, et al. Prevalence of chronic thromboembolic pulmonary hypertension after acute pulmonary embolism: prevalence of CTEPH after pulmonary embolism. Thromb Haemost 2014;112:598605 .

13. D'Armini AM. Diagnostic advances and opportunities in chronic thromboembolic pulmonary hypertension. Eur Respir Rev 2015;24:253-262.

14. Kang BJ, Lee SD, Oh YM, Lee JS. Improved survival of Korean patients with idiopathic pulmonary arterial hypertension after the introduction of targeted therapies. 
Heart Lung 2014;43:561-568.

15. Chemla D, Castelain V, Humbert M, et al. New formula for predicting mean pulmonary artery pressure using systolic pulmonary artery pressure. Chest 2004;126:13131317.

16. Condliffe R, Kiely DG, Gibbs JS, et al. Improved outcomes in medically and surgically treated chronic thromboembolic pulmonary hypertension. Am J Respir Crit Care Med 2008;177:1122-1127.

17. Tiede H, Hoeper MM, Richter M, Cacheris W, Hinzmann B, Mayer E. Global burden of chronic thromboembolic pulmonary hypertension (CTEPH): an epidemiological analysis. Eur Respir J 2014;44(Suppl 58):P2326.

18. Choi WI. Incidence of chronic thromboembolic pulmonary hypertension after pulmonary embolism: a retrospective analysis in a university teaching hospital. Clin Exp Thromb Hemost 2015;2:4-7.

19. Jang MJ, Bang SM, Oh D. Incidence of pregnancy-associated venous thromboembolism in Korea: from the Health Insurance Review and Assessment Service database. J Thromb Haemost 2011;9:2519-2521.

20. Tapson VF, Humbert M. Incidence and prevalence of chronic thromboembolic pulmonary hypertension: from acute to chronic pulmonary embolism. Proc Am Thorac Soc 2006;3:564-567.

21. Pepke-Zaba J, Delcroix M, Lang I, et al. Chronic thromboembolic pulmonary hypertension (CTEPH): results from an international prospective registry. Circulation 2011;124:1973-1981.

22. Nishimura R, Tanabe N, Sugiura T, et al. Improved survival in medically treated chronic thromboembolic pulmo- nary hypertension. Circ J 2013;77:2110-2117.

23. Kunieda T, Nakanishi N, Satoh T, Kyotani S, Okano Y, Nagaya N. Prognoses of primary pulmonary hypertension and chronic majorvessel thromboembolic pulmonary hypertension determined from cumulative survival curves. Intern Med 1999;38:543-546.

24. Riedel M, Stanek V, Widimsky J, Prerovsky I. Longterm follow-up of patients with pulmonary thromboembolism: late prognosis and evolution of hemodynamic and respiratory data. Chest 1982;81:151-158.

25. Corsico AG, D'Armini AM, Cerveri I, et al. Long-term outcome after pulmonary endarterectomy. Am J Respir Crit Care Med 2008;178:419-424.

26. Jenkins D. Pulmonary endarterectomy: the potentially curative treatment for patients with chronic thromboembolic pulmonary hypertension. Eur Respir Rev 2015;24:263-271.

27. Kunihara T, Gerdts J, Groesdonk H, et al. Predictors of postoperative outcome after pulmonary endarterectomy from a 14-year experience with 279 patients. Eur J Cardiothorac Surg 2011;40:154-161.

28. Galie N, Ghofrani HA, Torbicki A, et al. Sildenafil citrate therapy for pulmonary arterial hypertension. N Engl J Med 2005;353:2148-2157.

29. Simonneau G, D'Armini AM, Ghofrani HA, et al. Riociguat for the treatment of chronic thromboembolic pulmonary hypertension: a long-term extension study (CHEST-2). Eur Respir J 2015;45:1293-1302.

30. Papamatheakis DG, Kim NH. Advances in the management of chronic thromboembolic pulmonary hypertension. Curr Hypertens Rep 2015;17:582. 